\title{
To the problem of computer-aided design of gear-and-leverage mechanisms
}

\author{
Alexey Rivkin*, Alexandr Sobolev, Alexey Nekrasov, and Michael Arbuzov \\ Moscow State University of Technology “STANKIN” Machne Tool Department, 127055 Moscow, \\ Vadkovsky lane 3a, Russia
}

\begin{abstract}
The possibilities of using gear-lever mechanisms in modern mechanical engineering are described on the example of three mechanisms from different areas of industry. For practical application, a method of structural and kinematic analysis of gear-lever mechanisms is proposed, implemented using the program module developed by the authors, and an algorithm for kinematic calculation of a gear-lever three-wheeled articulated four-link, as the most common and used in mechanical engineering, is given.
\end{abstract}

\section{Introduction}

Gear-lever mechanisms (GLM) have found application in the field of mechanical engineering and instrument making. They allow you to implement complex patterns of movement of links $[1,2]$. Such mechanisms are used in feeding devices of technological equipment, chipbreaking devices of machine tools. By means of gear-lever mechanisms, polygonal profiles can be processed with high accuracy. Gear-lever mechanisms have good dynamic characteristics [3, 4, 5]. Despite the recent widespread use of Electromechanical (mechatronic) systems, gear-lever mechanisms have a promising potential for use in various technical systems $[6,7]$.

Fig. 1 shows a diagram of a gear-lever chip-breaking device. The gear-lever mechanism of the device has a large reverse angle $\sigma$ to ensure intermittent supply of cutting tools in lathes, which ensures the process of crushing the drain chips. In place of the replaceable gears of the machine, a gear-lever mechanism is installed instead of the usual transmission. On the body 1 , a gear 2 is installed that transmits rotation to the gear wheel 3 , rigidly connected to the disk 4 , in the slot of which the slider 6 moves with the help of a screw 5 . The gear $z_{\mathrm{b}}$ is rigidly connected to this slider, so that when these two links move along the slot of the disk 4 , the value of the wheel's $z_{\mathrm{b}}$ eccentricity or the length of the crank $A B$ of the gear-lever mechanism changes. The driven gear wheel is rigidly connected to the outer race of a freewheel 7. The sprocket of this coupling is rigidly connected to the running shaft of the machine. The drive shaft of the machine is always transmitted to its movement at the forward angle $\theta$, and the rotation at the reverse angle $\sigma$ is absorbed by the freewheel. When the crank is turned at an angle $\varphi_{\mathrm{w}}$, the machine's running shaft is standing and the cutter is cutting off the chips. When the crank is rotated at an angle of $360^{\circ}-\varphi_{\mathrm{w}}$, the cutter is fed and the running

\footnotetext{
*Corresponding author: alexey-rivkin@yandex.ru
} 
shaft is rotated at an angle $\theta$. In this case, the cutter receives an additional feed, which exactly compensates for the feed lost when the cutter is idle. Since the values of angles $\theta$ and $\sigma$ can vary widely when changing the length $l_{1}$, the combination of a gear-lever mechanism with a freewheel clutch gives a mechanism with a variable standing angle. At length $l_{1}=0$ the mechanism turns into a normal change gear train mechanism of the machine and intermittent cutting becomes continuous.

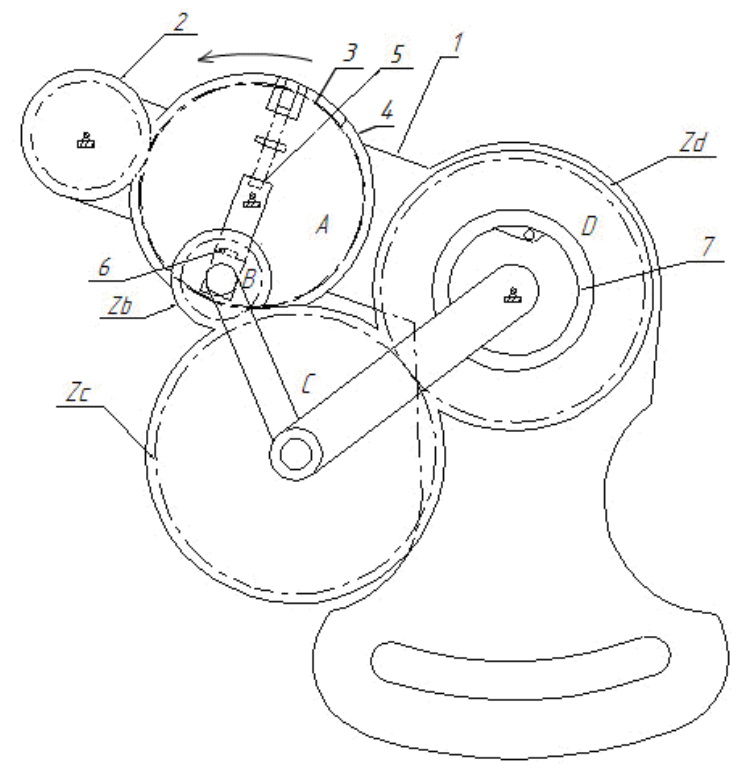

Fig. 1. Gear-lever chip breaking device for lathes.

Fig. 2 shows a diagram of the device for presses for automatic cutting of sheet parts of small and medium sizes with a single-punch stamp directly from a wide roll.

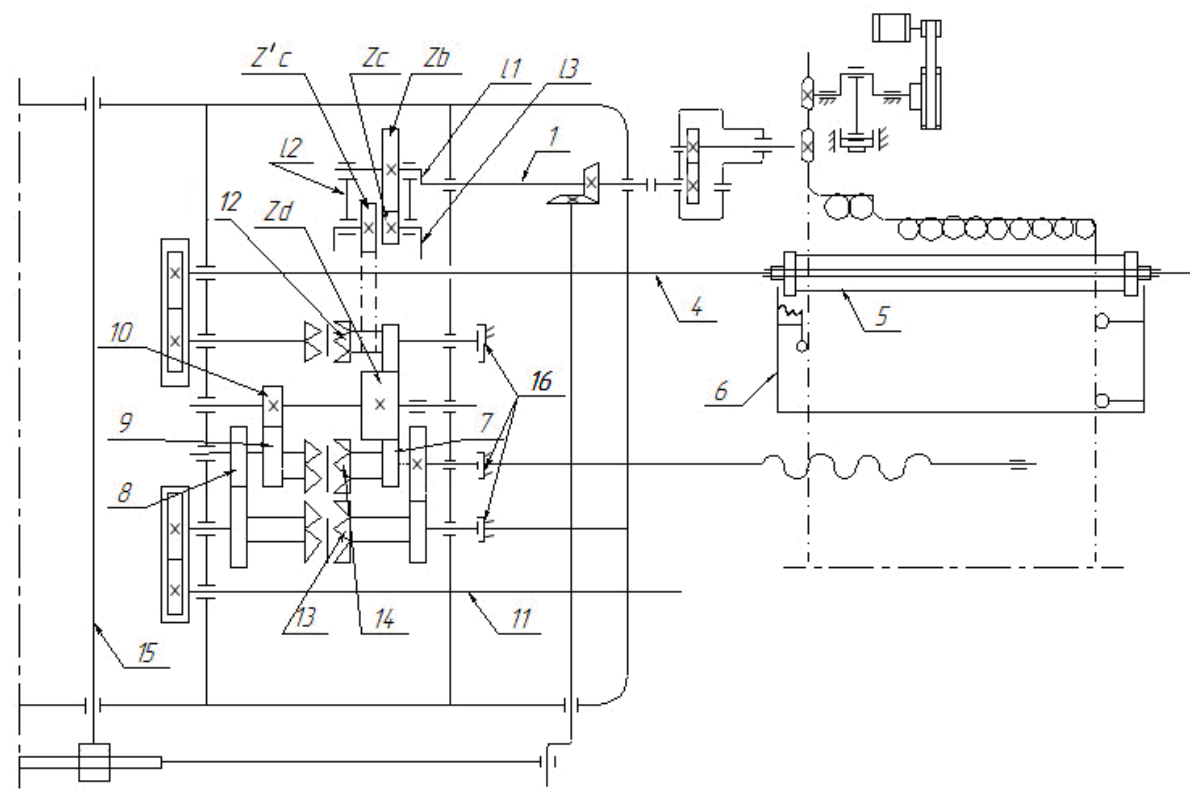

Fig. 2. Diagram of the feeding device for cutting parts directly from their sheet in presses. 
From the press shaft, uniform rotation is transmitted through a chain transmission and gearbox to the drive shaft 1 , which rotates the crank $l_{1}$ of the gear-lever mechanism. The gear $z_{\mathrm{d}}$ transmits periodic rotation with a stand to the output shaft 4 and from it to the feed rolls 5 of the feed unit 6 . From the gear $z_{\mathrm{d}}$ are brought into periodic rotation with standing the gears 7-8-9-10 of the reversing mechanism, which provides a reversible periodic movement of the node 6 along the axis of the shaft 4 using the output screw 11 . In this case, the gear $z_{\mathrm{d}}$ has a reverse angle $\sigma$ slightly exceeding the value of the backlash of the gears $z_{\mathrm{b}}-z_{\mathrm{c}}-z_{\mathrm{c}}^{\prime}-z_{\mathrm{d}}$, so, the combination of a gear-lever mechanism with a reverse mechanism makes it possible to compensate for gaps and elastic deformations that affect the accuracy of the roll feed when the screw 11 is reversed. The drive of the shaft 4 and the screw 11 is controlled by jaw clutches $12,13,14$, which move on the shafts under the action of levers driven from the camshaft 15 (the cams are not shown in the diagram). An electromagnet is used to rotate the camshaft 15 by $90^{\circ}$ during stand-up for each press cycle. The entire device works in combination with band-brakes 16 . The gear-lever device is also used in presses for periodic rotation of the feed rolls, which prevents inertial run-out of the rolls and ensures a longer feed cycle per revolution of the press shaft.

Fig. 3 shows a diagram of the device for feeding the paper tape of the packaging machine. Links 1, 2 and 5 form a crank-rocker mechanism, the axes of which $A, B, C$ and $D$ carry gears $z_{\mathrm{b}}, z_{\mathrm{c}}$ and $z_{\mathrm{d}}$. From the rocker 5 , freely sitting on the shaft 4 , the movement is transmitted by a link 6 with cams $E$ and $F$ to the shaft 7 of the knife 8 . The gear $z_{\mathrm{d}}$ is fixed to the shaft 4 , which transmits rotation to the shaft 3 through a gear pair $z_{\mathrm{e}}-z_{\mathrm{f}}$. The shaft rotates the rollers 10 , stretching the tape 9 under the knife 8 . With continuous rotation of the crank 1 (and the gear $z_{\mathrm{d}}$ ), the gear reports periodic movement with a stand to the rollers stretching the tape. When the crank is turned at an angle $\varphi_{\mathrm{w}}$, the knife 8 cuts the tape 9.
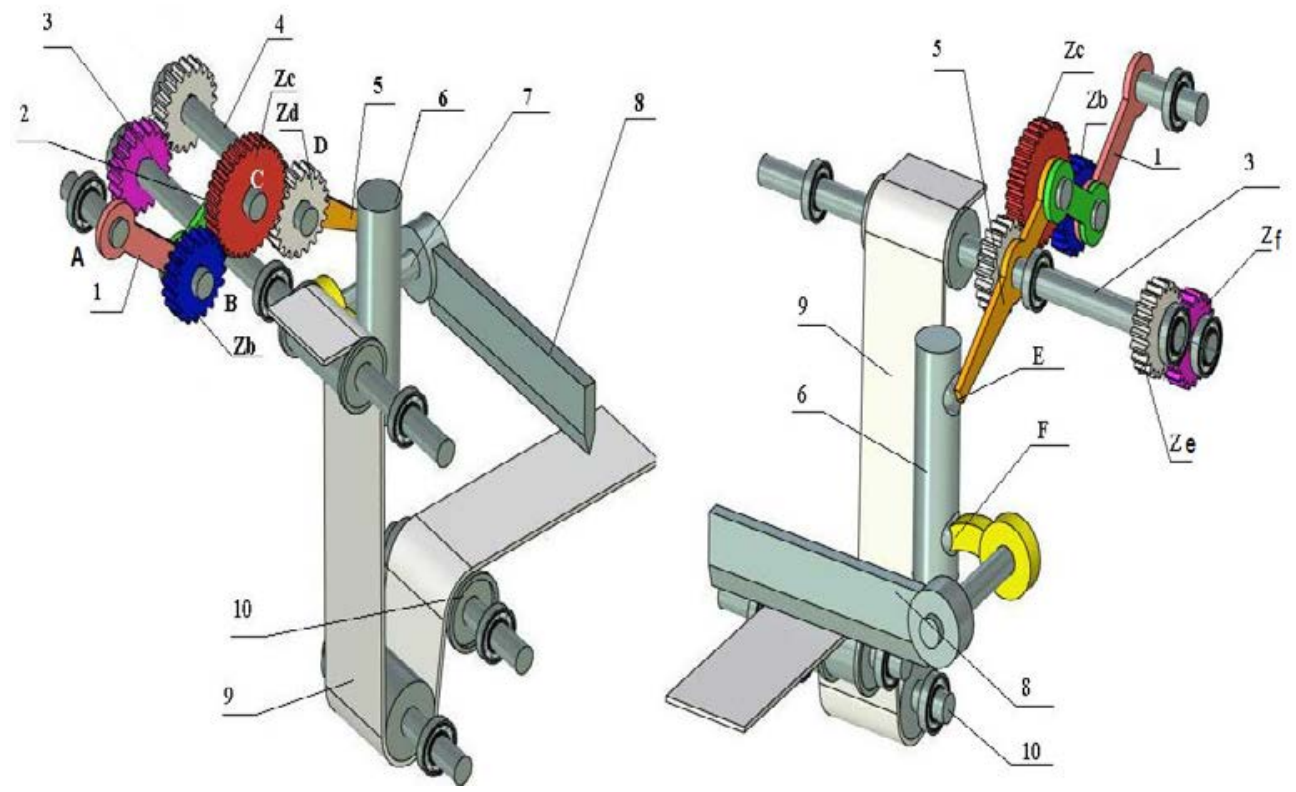

Fig. 3. Diagram of the paper belt feeding mechanism of the packaging machine. 


\section{Problem statement}

To design a gear-lever mechanism, it is necessary to solve synthesis problems and perform accurate calculations of kinematic and dynamic parameters. Analytical mathematical models of kinematic and dynamic analysis of gear-lever mechanisms are complex due to the need to perform labor-intensive calculation procedures, build cyclograms of operation and graphs of characteristics $[8,9]$. Thus, it is necessary to develop an application software tool for calculating and synthesizing gear-lever mechanisms in CAD systems.

Fig. 4 shows the algorithm for kinematic calculation of the gear-lever mechanism of a three-wheeled articulated four-link, as the most common and used in mechanical engineering.

Figure 4 shows the following notation:

$i_{\text {bd }}$ - the transmission ratio between the gears $z_{\mathrm{b}}$ and $z_{\mathrm{d}}$;

$i_{\mathrm{bc}}$ - the transmission ratio between the gears $z_{\mathrm{b}}$ and $z_{\mathrm{c}}$;

$l_{1}$ - the crank's length, $\mathrm{mm}$;

$l_{1 \text { min }}$ - the crank's minimum permissible length, $m m$;

$l_{1 \max }$ - the crank's maximum permissible length, $\mathrm{mm}$;

$l_{2}$ - the connecting rod length, $\mathrm{mm}$;

$l_{3}$ - the rocker length, $\mathrm{mm}$;

$r_{\mathrm{b}}$ - the gear $z_{\mathrm{b}}$ pitch radius, $\mathrm{mm}$;

$r_{\mathrm{c}}$ - the gear $z_{\mathrm{c}}$ pitch radius, $\mathrm{mm}$;

$r_{c}^{\prime}$ - the gear $z^{\prime}{ }_{c}$ pitch radius, $m m$;

$\lambda=\frac{l_{1}}{r_{b}} ; k=\frac{r_{c}}{r_{c}^{\prime}} ;$

$\omega_{\mathrm{d}} / \omega_{\mathrm{b}}-$ the analog of the angular velocity of the gear $z_{\mathrm{d}}$;

$\theta$ - the forward angle of the mechanism, deg.;

$\sigma$ - the reverse angle of the mechanism, deg.;

$\varphi_{\mathrm{w}}$ - the crank angle from gear $z_{\mathrm{b}}$ position $\varphi_{\mathrm{b}}^{\prime}$ to position $\varphi^{\prime \prime}{ }_{\mathrm{b}}$ at which the gear $z_{\mathrm{d}}$ makes a reverse move. The angles $\varphi^{\prime}{ }_{\mathrm{b}}$ and $\varphi^{\prime \prime}{ }_{\mathrm{b}}$ determine the position of the instantaneous stops of the gear $z_{\mathrm{d}}$, deg.;

$\varepsilon_{\mathrm{d}} / \omega^{2}{ }_{\mathrm{b}}$ - the analog of the angular acceleration of the gear $z_{\mathrm{d}}$;

$\varphi^{\prime}{ }_{b \varepsilon}, \varphi^{\prime \prime}{ }_{b \varepsilon}$ - the crank rotation angles at which $\varepsilon_{\mathrm{d}} / \omega^{2}{ }_{\mathrm{b}}=0$;

$\varphi^{\prime}{ }_{\mathrm{b} \mu}, \varphi^{\prime \prime}{ }_{\mathrm{b} \mu}-$ the crank rotation angles at which $\mu_{\mathrm{d}} / \omega^{2} \mathrm{~b}=0$;

$\mu_{\mathrm{d}}$ - the third time derivative of $\varphi_{\mathrm{d}}$ for the gear $z_{\mathrm{d}}$;

$\omega_{\mathrm{b}}$ - the angular velocity of the gear $z_{\mathrm{b}}, \mathrm{rad} / \mathrm{s}$;

$\omega_{\mathrm{d}}$ - the angular velocity of the gear $z_{\mathrm{d}}, \mathrm{rad} / \mathrm{s}$;

$\Delta l_{1}$ - the increment of the crank length during synthesis, $\mathrm{mm}$.

\section{Problem solution}

The authors have developed a software module in C\# [10, 11] that allows:

- to study the kinematics of gear-lever two-wheeled and three-forest articulated four-link vehicles;

- to investigate the area of existence of mechanisms, to carry out metrical synthesis;

- plot the position function and curves of analogs of angular velocities (changes in the gear ratio), angular accelerations, and jerk (the third production in time);

- automatically build simplified 2D diagrams of mechanisms in the T-Flex CAD environment.

Fig. 5 shows the shape of the developed software module. The module implements several algorithms for calculating the SAM, including the algorithm shown in Fig. 4. 

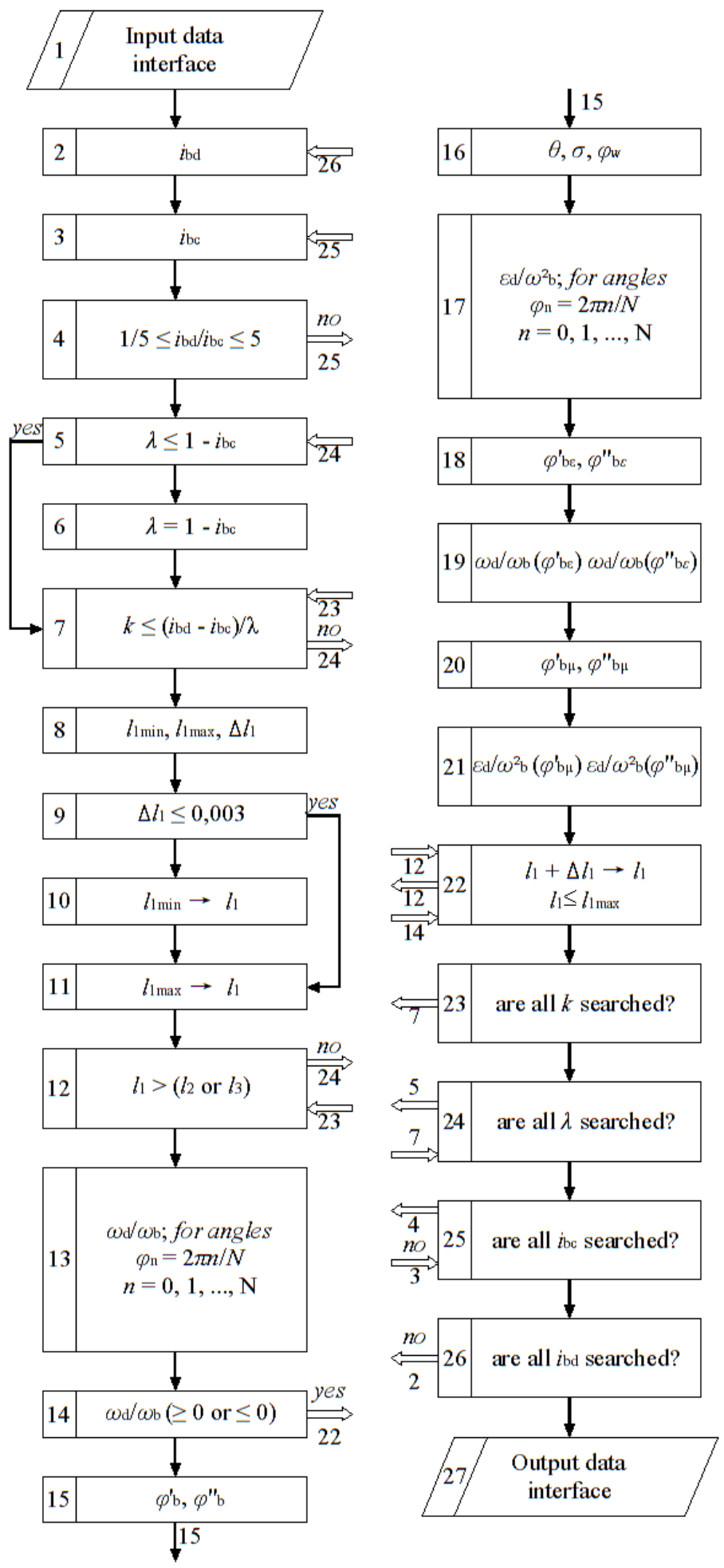

$19 \omega_{\mathrm{d}} / \omega_{\mathrm{b}}\left(\varphi^{\prime} \mathrm{be}\right) \omega_{\mathrm{d}} / \omega_{\mathrm{b}}\left(\varphi^{\prime \prime} \mathrm{bc}\right)$

20

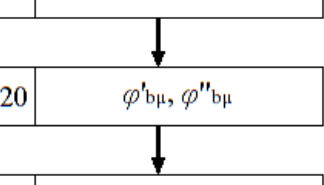

$21 \varepsilon \mathrm{d} / \omega^{2} \mathrm{~b}\left(\varphi^{\prime} \mathrm{b} \mu\right) \varepsilon d / \omega^{2} \mathrm{~b}\left(\varphi^{\prime \prime}{ }_{\mathrm{b} \mu}\right)$
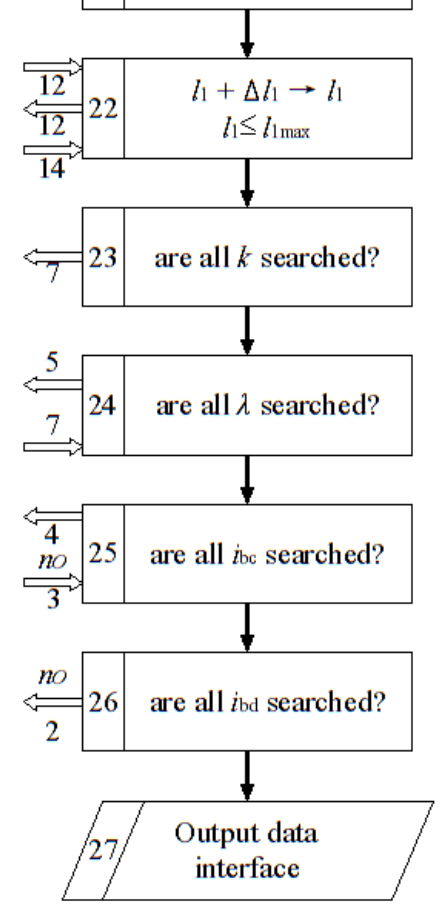

Fig. 4. The block diagram of kinematic calculation of the gear-lever mechanism of a three-wheeled articulated four-link. 


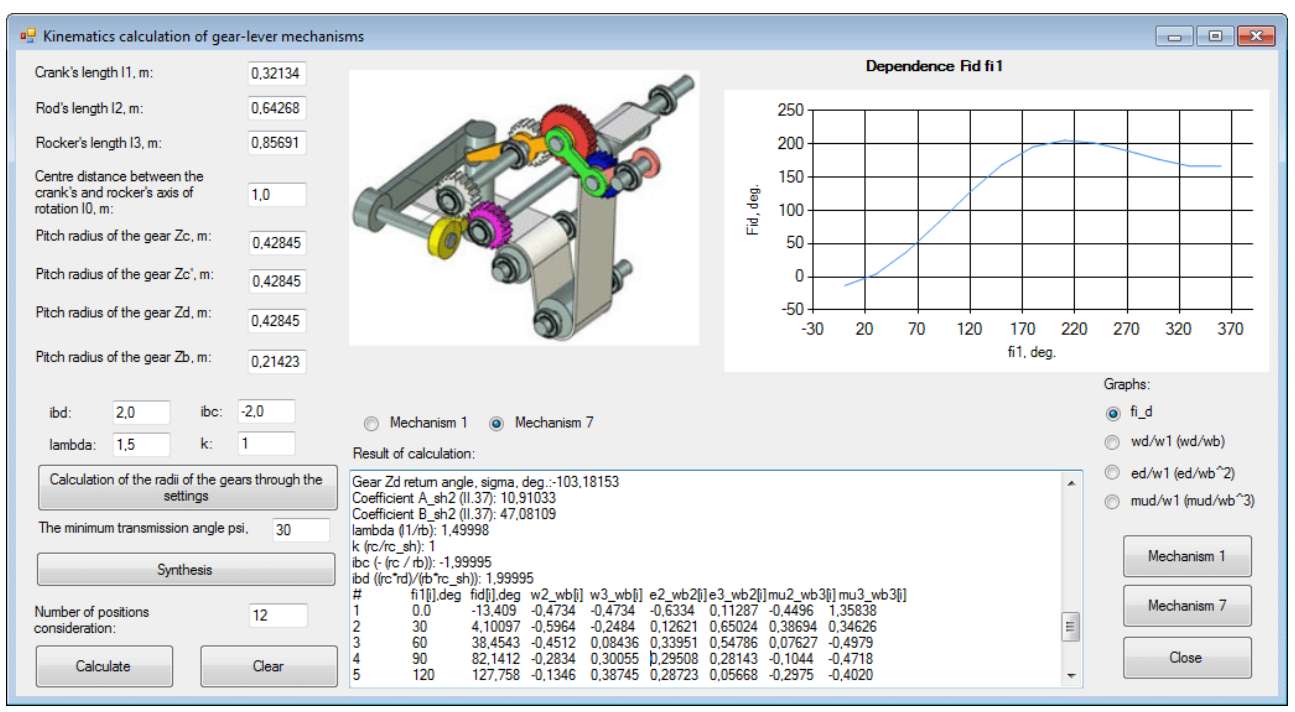

Fig. 5. View of the developed software module for calculating the gear-lever mechanism.

\section{Conclusions}

1. Currently, gear-lever mechanisms still have the potential to be used in modern automated process equipment [12].

2. Unfortunately, there are some difficulties in the synthesis and calculation of kinematic parameters of gear-lever mechanisms, which is still a deterrent to their widespread use in mechanical engineering and entails the use of expensive mechatronic systems.

3. To simplify the synthesis and calculation of gear-lever mechanisms, the authors proposed a software module that is constantly being updated. In the future, it is planned to automatically generate synthesized models of gear-lever mechanisms in the threedimensional space of the T-Flex CAD environment $[13,14,15]$.

4. The developed software module can be used in the educational process in the framework of the courses "Theory of mechanisms and machines" and "Technical mechanics" $[16,17]$.

\section{References}

1. A. Shagiakhmetov Bulletin of the SUSU, Series "Mechanical engineering industry $\mathbf{9 , 1}$ (83) 42-47 (2007) (in Russian)

2. A. Shagiakhmetov Bulletin of the SUSU, Series "Mechanical engineering industry 10, 25(97) 23-30 (2007) (in Russian)

3. T. Balabina, A. Mamaev, A. Sobolev Vestnik MSUT "STANKIN" $143-47$ (2017) in Russian

4. A. Shashkin Gear-lever mechanisms (Moscow, Mashinostroenie, 1971) (in Russian)

5. V. Karelin Design of lever and gear-lever mechanisms (Moscow, Mashinostroenie, 1986) (in Russian)

6. V. Chekanin, A. Chekanin Advances in Mechanical Engineering 22 33-38 (2015)

7. V. Chekanin, A. Chekanin A V Journal of Theoretical and Applied Information Technology 88 421-430 (2016)

8. I. Artobolevsky Mechanism and Machine Science (Moscow, Alliance, 2011) (in Russian)

9. N. Levitsky Mechanism and Machine Science (Moscow, Nauka, 1990) (in Russian) 
10. P. Drayton, B. Albahari, T. Neward C\# Language Poket Reference (O’Reilly, 2002)

11. C. Petzold Programming Microsoft Windows with C\# (Microsoft Press, 2002)

12. A. Rivkin, A. Nekrasov, A. Sobolev Materials Today: Proceedings. International Conference on Modern Trends in Manufacturing Technologies and Equipment $191982-$ 1984 (2019)

13. Y. Brovkina, A. Sobolev, A. Nekrasov Lecture Notes in Mechanical Engineering 11691179 (2019)

14. M. Arbuzov, A. Nekrasov, A Sobolev IOP Conf. Series: Materials Science and Engineering 709 (2020)

15. A. Nekrasov, M. Arbuzov, A.Sobolev Russian Engineering Research 35 442-446 (2015)

16. L. Vainer, U Gamolya Materials Science Forum 945 675-681 (2018)

17. E. Fazlulin, V. Ryabov, O. Yakovuk Pedagogy. Theory \& Practice 2(10) 54-58 (2018) (in Russian) 